\title{
Research on the Investment and Financing Mechanism for Development of Low-Carbon Economy
}

\author{
Lu Guan \\ School of Economics \& Management, Changchun University of Science and Technology \\ Changchun 130022, China \\ Tel: 86-136-6440-9239_E-mail: glcclgdx@sohu.com \\ Weiwei Zhang \\ School of Economics \& Management, Changchun University of Science and Technology \\ Changchun 130022, China \\ $\&$ \\ Postdoctoral Research Station of Theoretical Economics, Northeast Normal University \\ Changchun 130024, China \\ Tel: 86-133-3166-6858Ｅ-mail: zwwjldx@126.com
}

Received: June 6, 2012

Accepted: July 20, 2012

Online Published: August 21, 2012

doi:10.5430/bmr.v1n3p48

URL: http://dx.doi.org/10.5430/bmr.v1n3p48

This paper is sponsored by the Youth Foundation of Ministry of Education of China (11YJC790285), the "Eleventh Five-Year" Social Sciences Research of Jilin Provincial Education Department (2010JYT34), and the Social Science Research Foundation of Jilin Province (2011B205); financially supported by Science and Technology Commission of Jilin Province of China, Soft Science project. (20100604): "The study on Rural Labor Mobility in Jilin province and Institutional Innovation". This paper is also financially supported by Jilin Economics Research Center of Enterprise ---- the key humanities and social sciences base of Jilin Province.

\begin{abstract}
To develop low-carbon economy has been an inevitable choice for human social development, while an efficient investment and financing mechanism is the basic precondition for the smooth development of low-carbon economy. In this paper, authors firstly analyze main investment and financing modes in the world, and secondly investigate the investment and financing needs of China's low-carbon economy and the trouble. Finally, authors propose some suggestions, in the hope of building and improving the investment and financing mechanism for the development of low-carbon economy in China.
\end{abstract}

Keywords: Low-carbon economy, Investment and financing, Green credit

In recent years, lots of researches discuss about low-carbon economy, especially focusing on the trading mechanism of carbon products (Sonia et al., 2010; Dechun Yan, 2010). Although some literatures concern the issue of investment and financing mechanism of low-carbon economy, the conclusions and suggestions are shallow and mostly discuss one side of the mechanism, investment or financing. Actually, a complete and efficient investment and financing mechanism is the basic precondition for the smooth development of low-carbon economy. Therefore, in this paper we try to explore the whole investment and financing mechanism of low-carbon economy, in the hope of improving the investment and financing mechanism for the development of low-carbon economy in China.

\section{An international comparison between investment and financing modes for low-carbon economy}

The low-carbon economy begins early in foreign countries. Along with the development of low-carbon economy, it gradually formed several kinds of investment and financing modes, including the government-led financing mode, the credit agency-supported mode, the capital market financing mode, and the carbon emissions trading mode.

\subsection{The government-led public fiscal investment and financing mode.}

Government is the chief supplier of funds for the development of carbon economy. By means of legislation protection, fiscal investment, and taxation support, the government can dominate investments in low-carbon economy, enterprises, and projects. Europe, America, Japan and other developed countries have built relatively 
perfect legal framework in fields of energy conservation and low-carbon economy. Relevant acts related to climate change and development of low-carbon economy usually regulate fiscal budgets and financial arrangements for the government developing low-carbon economy.

\subsection{The green credit investment and financing by banks and other financial institutions.}

Based on the government-led fiscal investment and financing mechanism, developed countries employ some incentive policies, such as finance discount, to encourage banks and other credit institutions to participate in low-carbon economy, direct banks and relevant financial institutions to provide green credits for enterprises and projects focusing on developing new energies, reducing carbon emissions, and developing low-carbon technologies, and encourage them to give low-interest loans or unsecured loans to key projects that benefit energy conservation and pollution reduction. In order to fulfill the social responsibility and response to the call of government, financial agencies can provide financial supports for low-carbon enterprises by green financial activities.

\subsection{The investment and financing by carbon stock, carbon funds, and other capital market.}

Low-carbon enterprises are popular among investors in capital market, which thus gives birth to a new capital market in developed countries ------ the low-carbon industrial sector. The low-carbon industry has already become a newly-developed investment field in the capital market of developed countries. In recent years, some low-carbon industry-related ETF and mutual funds appear in international capital market. The statistics show that 12,000 hedge funds manage about 2 trillion dollars of assets in the world, and more than $5 \%$ hedge funds choose to invest in financial products related to environment and climate.

\subsection{The investment and financing by carbon trading and carbon derivatives.}

The "United Nations Framework Convention on Climate Change" and the "Kyoto Protocol" have founded the legal basis and market rules for global carbon emissions trading. Along with the fast expansion of global carbon emissions trading market, carbon credit has developed into a financial asset with investment values and liquidity. The "Kyoto Protocol" has introduced the Clean Development Mechanism (CDM), Emissions Trading (ET), and Joint Implementation (JI), and some major countries gradually develop the greenhouse gas emissions trading market, which make the emission of greenhouse gases, mainly carbon dioxide, become a new product circulating in international capital market.

\section{The investment and financing needs of China's low-carbon economy and the troubles}

To sponsor the emission reduction projects and construct relevant infrastructure demands huge sums of money. The development of China low-carbon economy also requires large amounts of money supply and flow mechanism.

\subsection{The investment and financing needs for China developing low-carbon economy}

The "Stern Report" estimates that it would avoid 5\%-20\% GDP loss per year in the future if invest 1\% GDP in low-carbon economy today. In the year 2010, China's GDP is 6 trillion dollars. Then, in order to achieve a transition to low-carbon economy, China needs to invest 60 billion dollars, nearly 4000 billion Yuan, in the field per year. A report by a Project Team of Development Research Center of the State Council of China estimates that China needs to add 1 trillion Yuan or even more additional investments in the field in order to achieve the goal of annually reducing 3.7\% emissions per GDP during the 10 years from 2010 to 2020, under the present policy of energy conservation and emissions reduction.

\subsection{The investment and financing trouble for China developing low-carbon economy}

The investment and financing trouble for China developing low-carbon economy is mainly from four aspects.

(1) The public financial investment in low-carbon economy is insufficient. China's investment in low- carbon environmental protection is still low. In 2009, for example, China invests 452.5 billion Yuan in environmental pollution control, accounting for $1.33 \%$ of GDP. However, global experiences show that as the investment in low-carbon environmental protection accounts for $1 \%-1.5 \%$ of GDP, it can control the trend of environmental degradation; while the percentage reaches $2 \%-3 \%$, it can improve the environment quality.

(2) Commercial banks are not so interested in investing in low-carbon economy. In China, commercial banks are still at the starting stage due to insufficient understanding and participation in the field. On July 30, 2007, Chinese commercial banks began to carry out the "Green Credit Policy" for environment protection. However, current conditions show that the implementation of this policy does not achieve an ideal effect because of unclear standards for market entrance, technologies, energy consumption, and pollution and low operability of green credit.

(3) The participation of capital market in the investment and financing of low-carbon economy is at a low degree. Data show that since the year 2006 only few listed companies are characterized by low-carbon economy, energy conservation, and environmental protection in Shanghai and Shenzhen Stock Exchanges. The share is merely about $10 \%$ of the total number of non-financial listed companies. It is still difficult for low-carbon enterprises listing in the 
Main Board and GEM, financing and issuing securities without supports of relevant policy. In addition to public financial investment and credit support, the capital market does not develop powerful financial supports for the development of low-carbon economy.

(4) The lack of relevant carbon financial derivatives for the development of low-carbon economy. Although China has a strong advantage of carbon emissions reduction and the potential for carbon emissions trading, carbon financial derivatives and the market are relatively backward, not yet developing the national carbon emissions trading market and platform in China.

\section{Build and improve the investment and financing mechanism for the development of low-carbon economy in China}

Further making best use of the investment and financing effect of public finance, commercial banks, security market, and derivatives market, building and improving the investment and financing mechanism for the development of low-carbon economy in China should be the direction for future policy.

\subsection{Strengthen the government-led public investment and financing}

Firstly, increase the government investment in low-carbon economy. The central and local government should invest more in low-carbon economy and build the government-supported investment and financial mechanism for the development of low-carbon economy. Secondly, establish the green taxation system. Impose environmental taxes, including carbon tax, at the right time, and increase the environmental tax rate gradually based on the low initial rate. Accelerate the reform of current resource tax and expand the taxation range by changing specific duty to ad valorem tax. Thirdly, enhance the policy support. Use tax incentives, financial subsidies, and government procurement to improve the attractiveness of low-carbon economy.

\subsection{Improve the green credit investment and financing intensity}

In future, Chinese commercial banks and other credit institutions can learn from and follow the Equator Principles, gradually becoming Equator Banks. Accelerate to perfect the green credit system for low- carbon economy, focus on supporting low-carbon economic projects and enterprises, provide more green credits for low-carbon economy, expand the size of green credits, give more preferential loan conditions for low-carbon industry, give more supports for the financing of small and medium-sized low-carbon enterprises, reduce and even eliminate the financing troubles of low-carbon economy.

\subsection{Promote the investment and financing in low-carbon capital market}

In order to promote the investment and financing in low-carbon capital market, we can try to opening a "green channel" for low-carbon energy-saving and emissions- reduction enterprises' public offering and listing. Give priority to the low-carbon enterprises that operate properly with qualified assets and technologies and allow them to list in the Main Board, so as to increase the number of listing low-carbon enterprises in the Main Board as soon as possible. Encourage and support high-tech small and medium-sized enterprises in fields of low-carbon technological development and application to enter the low-carbon GEM, and provide direct financial supports for their development and growth. Give first approval of low-carbon enterprises and projects issuing low-carbon bonds, medium term notes, and short-term financing bills if they are in accordance with the requirements of developing lowcarbon economy, helping them to raising funds rapidly and effectively for development.

\subsection{Explore private financing for low-carbon economy}

Establish various smooth channels for private finance participating in low-carbon economic financing and development, and build an effective mechanism for private funds joining in low-carbon economy. By means of improving the legal environment, building a tracing and monitoring system, developing risks education, and Sharing private financing information regularly, we can promote the orderly development of private finance, and achieve the multi-level and multi-channel financing and development of low-carbon economy.

\section{References}

Project Team of Development Research Center of the State Council of China. (2009). Greenhouse gas emission reduction: a theoretical framework and global solution. Economic Research Journal. No.3.

Sonia Labatt \& Rodney R. White. (2006). Carbon Finance: The Financial Implications of Climate Change. Published: Environmental Finance magazine.

Wu, Yuyu. (2009). Carbon finance development and carbon finance mechanism innovation strategy in China. Shanghai Finance. No.10.

Yan, Dechun. (2010). Developing China Carbon Market: Initiative Scheme Integrating Carbon Futures and Carbon Fund. Beijing: Economic Science Press. 